\title{
Progressive Medulloblastoma
}

National Cancer Institute

\section{Source}

National Cancer Institute. Progressive Medulloblastoma. NCI Thesaurus. Code C147111.

Medulloblastoma that is increasing in scope or severity. 